\title{
Are Teacher Ratings and Parent Ratings Differently Associated with Children's Intelligence and Cognitive Performance?
}

\author{
Soo-Churl Cho ${ }^{1}$, Hyo-Won $\mathrm{Kim}^{2} \bowtie$, Boong-Nyun Kim${ }^{1}$, Min-Sup Shin ${ }^{1}$, \\ Hee Jeong $\mathrm{Yoo}^{3}$, Jae-Won Kim${ }^{1}$, Soo-Young Bhang ${ }^{4}$ and In $\mathrm{Hee} \mathrm{Cho}^{5}$ \\ 'Department of Child and Adolescent Psychiatry, Seoul National University College of Medicine, Seoul, Korea \\ ${ }^{2}$ Department of Psychiatry, University of Ulsan College of Medicine, Asan Medical Center, Seoul, Korea \\ ${ }^{3}$ Department of Psychiatry, Seoul National University Bundang Hospital, Seongnam, Korea \\ ${ }^{4}$ Department of Psychiatry, Ulsan University Hospital, Ulsan, Korea \\ ${ }^{5}$ Department of Psychiatry, Gachon University of Medicine and Science, Incheon, Korea
}

\begin{abstract}
Objective The present study investigated whether teacher ratings and parent ratings of inattentive or hyperactive/impulsive symptoms were differently associated with intelligence or cognitive performance in Korean children.

Methods Six hundred sixty-seven children were recruited from nine schools in five Korean cities. The teachers and parents of 580 of these children ( $9.0 \pm 0.7$ years old, 333 boys and 306 girls) completed the Korean version of the Attention-Deficit/Hyperactivity Disorder Rating Scales (K-ARS), and the children performed the abbreviated form of the Korean Educational Development Institute-Wechsler Intelligence Scales (KEDI-WISC) and a neurocognitive battery consisting of the continuous performance test, the Children's Color Trails Test, and the Stroop Color-Word Test. Diagnosis of full-syndrome and subthreshold attention-deficit/hyperactivity disorder (ADHD) were based on the Diagnostic Interview Schedule for Children Version-IV (DISC-IV).

Results The level of agreement between teacher and parent ratings was low $(r=0.21-0.26)$ in children with full-syndrome and subthreshold ADHD and low to moderate ( $r=0.31-0.41)$ in the normative sample. Teacher-rated ARS showed significant correlations with most subscores of KEDI-WISC and the neurocognitive battery both in the normative sample ( $\mathrm{r}=-0.50-0.37)$ and in children with full-syndrome and subthreshold ADHD ( $r=-0.26-0.29)$. Correlations between parent-rated ARS and cognitive tests were lower and were found in fewer subscales of tests.
\end{abstract}

Conclusion These results suggest the importance of considering the teacher's report of a child's school functioning during the assessment of ADHD.

Psychiatry Investig 2011;8:15-21

Key Words Attention-deficit/hyperactivity disorder, Cognition, Intelligence, Parent and teacher rating scale.

\section{INTRODUCTION}

Attention-deficit/hyperactivity disorder (ADHD) is the most common childhood psychiatric disorder, affecting about $5 \%$ of the population worldwide. ${ }^{1}$ The core symptoms of ADHD (inattention, hyperactivity, and impulsivity) often give rise to significant functional problems, such as school difficulties, academic underachievement, troublesome interpersonal relation-

Received: June 21, 2010 Revised: September 4, 2010

Accepted: November 3, 2010 Available online: December 3, 2010

$\triangle$ Correspondence: Hyo-Won Kim, MD, PhD

Department of Psychiatry, University of Ulsan College of Medicine, Asan Medical Center, 86 Asanbyeongwon-gil, Songpa-gu, Seoul 138-736, Korea

Tel: +82-2-3010-3414, Fax: +82-2-485-8381, E-mail: shingubi@gmail.com

(a) This is an Open Access article distributed under the terms of the Creative Commons Attribution Non-Commercial License (http://creativecommons.org/licenses/bync/3.0) which permits unrestricted non-commercial use, distribution, and reproduction in any medium, provided the original work is properly cited. ships with family members and peers, and low self-esteem. ${ }^{2}$ According to the Diagnostic and Statistical Manual of Mental Disorders-4th Edition (DSM-IV), impairment from the symptoms in two or more settings and at least six symptoms of inattention and/or six symptoms of hyperactivity/impulsivity must be present for a diagnosis of ADHD to be made. In general, the cross-setting criterion for $\mathrm{ADHD}$ has been ascertained in terms of home and school behaviors as reported by parents and teachers. However, the agreement between parent and teacher reports about the symptoms of $\mathrm{ADHD}$ has been found to be low to moderate in both children with $\mathrm{ADHD}^{3-5}$ and typically developing children. ${ }^{6.7}$ The general literature on behavior rating scales has found that teachers report more behavior problems and $\mathrm{ADHD}$ symptoms than do parents ${ }^{8}$ and that parent reports of in-school ADHD behavior correlate more highly with their own reports of their child's behavior at home than with 
teacher reports of their child's behavior at school. ${ }^{3}$ On the other hand, other studies have reported increased symptoms of ADHD in parent ratings. ${ }^{9}$ In contrast to poor agreement between parent-and teacher-rated symptoms of $\mathrm{ADHD}$, good convergence between reports from groups of parents and teachers during methylphenidate ${ }^{10}$ and atomoxetine trials ${ }^{11}$ have been identified. Although many studies have addressed the issue of parent-teacher agreement for the diagnosis of ADHD and for assessments of change during treatment, only a few researches has focused on the association between parent or teacher ratings of children's behavior and cognitive performance.

Children with ADHD are reported to exhibit deficits in cognitive functions such as working memory, strategies and planning, selective attention, sustained attention, attention switching, resistance to interference, and inhibition. ${ }^{2}$ Performance on neuropsychological measures, particularly executive function tests, are considered to be sensitive to $\mathrm{ADHD}$, pointing to a possible underlying neuropsychological process and to a closer connection to genetic functionality. ${ }^{12}$ Mares et al. ${ }^{7}$ found that teachers reported greater variety and severity of executive function impairment than did parents, based on rating scales. However, only a few studies have evaluated the relationships between parent or teacher ratings of children's behavior and objectively measured cognitive performance. Thus, the purpose of this study was to investigate whether teacher ratings and parent ratings of inattentive or hyperactive/impulsive symptoms differed in their association with intelligence or cognitive performance in Korean children.

\section{METHODS}

\section{Study population and recruitment}

The present study was conducted from April through October 2008. Participants were recruited from third- and fourthgrade students (age range 8-10) in five Korean cities: Seoul (metropolitan), Seongnam (suburban), Ulsan and Incheon (industrial), and Yeoncheon (rural). We selected between one and three schools per area (nine in total) that best represented the local demographics. Of 1,000 eligible children, the parents of 667 gave consent for their child to participate in the study. Thus, the total response rate was $66.7 \%$. The research design of this study has previously been described in detail. ${ }^{13}$ The nine selected schools agreed to participate in the study, which was approved by the Institutional Review Board of the Seoul National University Hospital. The parents were informed about the study through letters sent by the teachers. Written informed consent was obtained from the parents before each interview.

\section{Assessment of ADHD symptoms and diagnosis}

Inattentiveness and hyperactivity were evaluated both by par- ents and by teachers based on the Korean version of the ADHD rating scale (K-ARS). The ADHD Rating Scale (ARS) assesses the severity of ADHD symptoms. It was designed by Dupaul and his collegues ${ }^{14}$ and contains 18 items; nine of these assess inattention, and nine are related to hyperactivity and impulsivity. The K-ARS parent and teacher forms are considered to have high validity and reliability. ${ }^{6}$

Full-syndrome and subthreshold ADHD were determined based on the parent version of Diagnostic Interview Schedule for Children Version-IV (DISC-IV), a highly structured diagnostic instrument. Full syndrome ADHD was defined according to DSM-IV criteria for ADHD. Subthreshold ADHD was operationally defined as the presence of at least three and no more than five inattentive and/or hyperactive/impulsive symptoms. Some impairment from the symptoms needed to be present in two or more settings. Children had also to fulfill DSMIV ADHD age-of-onset and impairment criteria to qualify for a diagnosis of subthreshold ADHD. This definition of subthreshold ADHD is identical to that implemented in previous research. ${ }^{15,16}$ Good test-retest reliability of the DISC-IV has been reported. ${ }^{17}$ The reliability and validity of the Korean version of the DISC-IV has been previously determined. ${ }^{18}$

\section{Assessment of neurocognitive function}

The abbreviated form of the Korean Educational Development Institute-Wechsler Intelligence Scales for Children (KEDI-WISC) and a neurocognitive battery consisting of the continuous performance test (CPT), the Children's Color Trails Test (CCTT), and the Stroop Color-Word Test were administered to each child. All of the data are presented as T-scores adjusted for age and gender. Higher T-scores indicate better function in all tests except the CPT, in which lower T-scores indicate better attention and response inhibition ability.

\section{KEDI-WISC, the abbreviated form}

The abbreviated form of the KEDI-WISC ${ }^{19}$ tests vocabulary, arithmetic, picture arrangement, and block design. Scores from this battery are highly correlated with the WISC full-scale IQ ${ }^{20}$

\section{CPT}

A computerized $\mathrm{CPT}^{21,22}$ was used to measure cognitive functions. The four major variables recorded were 1) omission errors, 2) commission errors, 3) response times, and 4) the standard deviations of the response times for correct responses to the target (response time variability).

\section{CCTT}

The CCTT is based on the adult version of the Color Trails Test. ${ }^{23}$ The Korean version was standardized by Shin and Koo. ${ }^{24}$ Two time scores (the total time to finish CCTT- 1 and CCTT- 
2) and the difference interference index (CCTT-2 total time to finish-CCTT-1 total time to finish) were assessed.

\section{Stroop Color-Word Test}

The Stroop Color-Word Test was developed by Charles Gordon for children aged 5-14. ${ }^{25}$ The Korean version was standardized by Shin and Park. ${ }^{26}$ The interference scores were calculated as the correct number of concordant color letters (color score) -correct number of discordant color letters (color-word score).

\section{Data analysis}

Student's t-tests or analyses of variance were used for continuous variables, and the chi-squared test was used for categorical variables. Pearson correlation tests were used to determine the relationship between the parent or teacher rating and the intelligence and cognitive performance. All statistical analyses were performed using Statistical Package for the Social Sciences (SPSS) 15.0 for Windows (SPSS Inc., Chicago, IL, USA). All comparisons were two-tailed, and statistical significance was defined as $\mathrm{p}<0.05$.
The level of clinical significance was considered to be low when intraclass correlations were below 0.40 , moderate between 0.40 and 0.59 , good between 0.60 and 0.74 , and excellent when they were between 0.75 and $1.00 .^{27}$

\section{RESULTS}

\section{Study population characteristics}

A total of 667 children were recruited from nine schools in five Korean cities. The number of participants in each city was as follows: Seoul, 279; Seongnam, 73; Incheon, 126; Ulsan, 113; and Yeoncheon, 76. Of the 667 children, teacher-rated ARS results were available for 643 (96.4\%), parent-rated ARS ratings were available for 597 (89.5\%), and both measures were available for 580 children (87.0\%).

The mean age of the 580 subjects included in the final analysis was 9.0 years \pm 0.7 , (range 8-11); 306 (49.8\%) were female, and 333 (50.2\%) were male. No significant differences in age, gender, father's educational level, birth-weight, teacher-rated ARS, or parent-rated ARS were found between the children includ-

Table 1. Comparison of parent- and teacher-rated ARS and cognitive tests for children with and without full-syndrome and subthreshold ADHD

\begin{tabular}{|c|c|c|c|c|}
\hline & \multirow{2}{*}{$\begin{array}{l}\text { Full-syndrome/Subthreshold ADHD } \\
\qquad(\mathrm{N}=88)\end{array}$} & \multirow{2}{*}{$\begin{array}{c}\text { Non-ADHD } \\
(\mathrm{N}=410)\end{array}$} & \multirow{2}{*}{$\mathrm{t}$} & \multirow{2}{*}{ p-value } \\
\hline & & & & \\
\hline Parent-rated ARS, total & $15.1(13.7)$ & $7.6(10.4)$ & 4.9 & $<0.001$ \\
\hline Teacher-rated ARS, total & $17.7(10.5)$ & $7.4(7.0)$ & 8.8 & $<0.001$ \\
\hline \multicolumn{5}{|l|}{ Abbreviated KEDI-WISC } \\
\hline Mathematics & $9.9(3.1)$ & $10.9(2.7)$ & -3.09 & 0.002 \\
\hline Vocabulary & $11.7(3.3)$ & $13.1(3.4)$ & -3.50 & 0.001 \\
\hline Block design & $12.6(3.4)$ & $13.2(3.2)$ & -1.47 & 0.143 \\
\hline Picture arrangement & $10.5(3.1)$ & $10.8(3.1)$ & -0.88 & 0.380 \\
\hline FSIQ & $107.4(15.8)$ & $112.6(14.2)$ & -2.85 & 0.005 \\
\hline \multicolumn{5}{|l|}{ Continuous performance tests } \\
\hline Omission errors & $69.7(28.9)$ & $60.8(23.1)$ & 2.72 & 0.008 \\
\hline Commission errors & $82.5(30.5)$ & $69.5(27.7)$ & 3.70 & $<0.001$ \\
\hline Response times & $49.8(16.0)$ & $48.3(11.4)$ & 1.05 & 0.293 \\
\hline Response times variability & $79.7(38.8)$ & $67.3(31.3)$ & 2.79 & 0.006 \\
\hline \multicolumn{5}{|l|}{ Children's Color Trails Tests } \\
\hline CCTT 1 & $25.6(8.5)$ & $23.8(8.5)$ & 1.82 & 0.069 \\
\hline CCTT 2 & $53.9(17.4)$ & $49.8(13.7)$ & 2.47 & 0.014 \\
\hline Interference & $50.0(10.8)$ & $51.4(9.9)$ & -1.20 & 0.230 \\
\hline \multicolumn{5}{|l|}{ Stroop Color-Word Tests } \\
\hline Word & $46.1(12.1)$ & $49.7(11.0)$ & -2.79 & 0.006 \\
\hline Color & $47.9(11.9)$ & $51.7(10.7)$ & -2.92 & 0.004 \\
\hline Color-word & $46.4(12.9)$ & $51.0(12.0)$ & -3.17 & 0.002 \\
\hline Interference & $50.0(10.6)$ & $49.2(11.9)$ & 0.56 & 0.572 \\
\hline
\end{tabular}

ARS: attention-deficit/hyperactivity disorder rating scale, ADHD: attention-deficit/hyperactivity disorder, CCTT: Children's Color Trails Test, KEDI-WISC: Korean Educational Development Institute-Wechsler Intelligence Scales for Children, FSIQ: full scale intelligent quotient 
Table 2. Pearson correlations between the parent- and teacher-rated ARS in normative sample $(\mathrm{N}=580)$

\begin{tabular}{clccc}
\hline & & \multicolumn{2}{c}{ Parent-rated ARS } \\
\cline { 3 - 5 } & & Inattention & Hyperactivity/Impulsivity & Total \\
\hline \multirow{2}{*}{ Teacher-rated ARS } & Inattention & $0.41^{* * *}$ & $0.34^{* * *}$ & $0.40^{* * *}$ \\
& Hyperactivity/impulsivity & $0.31^{* * *}$ & $0.36^{* * *}$ & $0.35^{* * *}$ \\
& Total & $0.39^{* * *}$ & $0.37^{* * *}$ & $0.40^{* * *}$ \\
\hline
\end{tabular}

${ }^{* * *} \mathrm{p}<0.001$. ARS: attention-deficit/hyperactivity disorder rating scale

Table 3. Pearson correlations between the parent- and teacher-rated ARS and measures of the cognitive function in normative sample ( $N=580)$

\begin{tabular}{|c|c|c|c|c|c|c|}
\hline & \multicolumn{3}{|c|}{ Teacher-rated ARS } & \multicolumn{3}{|c|}{ Parent-rated ARS } \\
\hline & Inattention & $\begin{array}{l}\text { Hyperactivity/ } \\
\text { Impulsivity }\end{array}$ & Total & Inattention & $\begin{array}{c}\text { Hyperactivity/ } \\
\text { Impulsivity }\end{array}$ & Total \\
\hline \multicolumn{7}{|l|}{ Abbreviated KEDI-WISC } \\
\hline Mathematics & $-0.20^{* * *}$ & -0.04 & $-0.14^{* *}$ & $-0.12^{* *}$ & -0.06 & $-0.10^{*}$ \\
\hline Vocabulary & $-0.21^{* * *}$ & $-0.10^{*}$ & $-0.17^{* * *}$ & $-0.10^{*}$ & -0.02 & -0.07 \\
\hline Block design & $-0.17^{* * *}$ & -0.08 & $-0.14^{* *}$ & -0.07 & -0.01 & -0.05 \\
\hline Picture arrangement & $-0.18^{* * *}$ & $-0.13^{* *}$ & $-0.16^{* * *}$ & $-0.10^{*}$ & -0.07 & $-0.09^{*}$ \\
\hline FSIQ & $-0.26^{* * *}$ & $-0.13^{* *}$ & $-0.21^{* * *}$ & $-0.14^{* *}$ & -0.06 & $-0.11^{* *}$ \\
\hline \multicolumn{7}{|l|}{ Continuous performance tests } \\
\hline Omission errors & $0.25^{* * *}$ & $0.18^{* * *}$ & $0.23^{* * *}$ & $0.12^{* *}$ & $0.11^{* *}$ & $0.12^{* *}$ \\
\hline Commission errors & $0.28^{* * *}$ & $0.24^{* * *}$ & $0.28^{* * *}$ & $0.15^{* * *}$ & $0.13^{* *}$ & $0.15^{* * *}$ \\
\hline Response times & $0.11^{* *}$ & $0.12^{* *}$ & $0.12^{* *}$ & -0.01 & 0.02 & 0.00 \\
\hline Response times variability & $0.27^{* * *}$ & $0.27^{* * *}$ & $0.29^{* * *}$ & $0.13^{* *}$ & $0.16^{* * *}$ & $0.15^{* * *}$ \\
\hline \multicolumn{7}{|l|}{ Children's Color Trails Tests } \\
\hline CCTT 1 & $0.10^{*}$ & 0.08 & $0.09^{*}$ & 0.05 & 0.05 & 0.05 \\
\hline CCTT 2 & $0.23^{* * *}$ & $0.13^{* *}$ & $0.19^{* * *}$ & 0.06 & -0.01 & 0.03 \\
\hline Interference & $-0.20^{* * *}$ & -0.08 & $-0.15^{* * *}$ & -0.04 & 0.05 & 0.00 \\
\hline \multicolumn{7}{|l|}{ Stroop Color-Word Tests } \\
\hline Word & $-0.14^{* *}$ & -0.03 & $-0.10^{*}$ & $-0.09^{*}$ & -0.02 & -0.07 \\
\hline Color & $-0.20^{* * *}$ & $-0.10^{*}$ & $-0.16^{* * *}$ & $-0.11^{* *}$ & -0.06 & $-0.10^{*}$ \\
\hline Color-word & $-0.27^{* * *}$ & $-0.16^{* * *}$ & $-0.23^{* * *}$ & $-0.15^{* * *}$ & $-0.10^{*}$ & $-0.14^{* *}$ \\
\hline Interference & 0.00 & 0.00 & 0.00 & 0.01 & 0.01 & 0.01 \\
\hline
\end{tabular}

${ }^{*} \mathrm{p}<0.05,{ }^{* *} \mathrm{p}<0.01,{ }^{* * *} \mathrm{p}<0.001$. ARS: attention-deficit/hyperactivity disorder rating scale, KEDI-WISC: Korean Educational Development Institute-Wechsler Intelligence Scales for Children, FSIQ: full scale intelligent quotient

ed and those excluded from the analysis $(\mathrm{p}=0.284, \mathrm{p}=0.382, \mathrm{p}=$ $0.934, \mathrm{p}=0.230, \mathrm{p}=0.641$, and $\mathrm{p}=0.595$, respectively).

Among the 580 children, 20 (3.4\%) were diagnosed with fullsyndrome ADHD, and 68 (11.7\%) with subthreshold ADHD. The mean ages of the full-syndrome and subthreshold ADHD were $9.2(\mathrm{SD}=0.8)$ and $9.0(\mathrm{SD}=0.7)$, respectively. Eighteen (90.0\%) of the full-syndrome ADHD and 33 (48.5\%) of the subthreshold ADHD were boys. Among 20 children with full-syndrome $\mathrm{ADHD}, 10$ (50.0\%) were predominantly inattentive type, 6 (30.0\%) were combined type, and 4 (20\%) were predominantly hyperactive-impulsive type. The two girls with full-syndrome ADHD were predominantly inattentive type. There were sig- nificant differences in parent- and teacher-rated ARS and cognitive tests between children with and without ADHD except Block Design and Picture Arrangement on abbreviated KEDIWISC, Stroop interference, CCTT 1 and interference on CCTT, reaction times on the CPT (Table 1).

Table 2 shows Pearson correlations between teacher-rated and parent-rated ARS among all 580 children. All sub-scores of teacher-rated and parent-rated ARS were weakly to moderately correlated. The correlations between teacher-rated and parent-rated ARS and intelligence or the cognitive performance are shown in Table 3. The inattention sub-scores and total scores of teacher-rated ARS were correlated with all sub-scores of the ab- 
breviated KEDI-WISC, CPT, CCTT, and Stroop tests except for Stroop interference. The hyperactivity/impulsivity sub-scores of teacher-rated ARS were associated with Vocabulary and Picture Arrangement sub-scores of KEDI-WISC, all sub-scores of the CPT, the CCTT2 sub-score of the CCTT, and the Color and Color-Word sub-scores of the Stroop test. The parent-rated ARS was also associated with some sub-scores of the KEDI-WISC, CPT, and Stroop test; the pattern was similar to that for the teacher-rated ARS, although the correlations were weak.

Among full-syndrome and subthreshold ADHD children, a positive association was found between parent-rated and teach- er-rated inattention and between parent-rated and teacher-rated hyperactivity/impulsivity (Table 4). Moreover, teacher-rated ARS was negatively associated with intelligence, as measured by the KEDI-WISC, and cognitive performance, as assessed by the CPT, CCTT, and Stroop tests.

In the parent-rated ARS, inattention sub-scores showed a significant association with the response times of the CPT only, and hyperactivity/impulsivity sub-scores showed significant associations with the Vocabulary sub-score of the KEDI-WISC only (Table 5).

Table 4. Pearson correlations between the parent- and teacher-rated ARS in children diagnosed with full-syndrome and subthreshold $\operatorname{ADHD}(\mathrm{N}=88)$

\begin{tabular}{llccc}
\hline & & \multicolumn{3}{c}{ Parent-rated ARS } \\
\cline { 3 - 5 } & & Inattention & Hyperactivity/impulsivity & Total \\
\hline \multirow{2}{*}{ Teacher-rated ARS } & Inattention & $0.26^{*}$ & 0.19 & $0.24^{*}$ \\
& Hyperactivity/impulsivity & 0.12 & $0.22^{*}$ & 0.17 \\
& Total & $0.21^{*}$ & $0.22^{*}$ & $0.23^{*}$ \\
\hline
\end{tabular}

${ }^{*} \mathrm{p}<0.05$. ADHD: attention-deficit/hyperactivity disorder, ARS: attention-deficit/hyperactivity disorder rating scale

Table 5. Pearson correlations between the parent- and teacher-rated ARS and measures of the cognitive function in children diagnosed with full-syndrome and subthreshold ADHD (N=88)

\begin{tabular}{|c|c|c|c|c|c|c|}
\hline & \multicolumn{3}{|c|}{ Teacher-rated ARS } & \multicolumn{3}{|c|}{ Parent-rated ARS } \\
\hline & Inattention & $\begin{array}{c}\text { Hyperactivity/ } \\
\text { impulsivity }\end{array}$ & Total & Inattention & $\begin{array}{c}\text { Hyperactivity/ } \\
\text { impulsivity }\end{array}$ & Total \\
\hline \multicolumn{7}{|l|}{ Abbreviated KEDI-WISC } \\
\hline Mathematics & $-0.33^{* *}$ & $-0.21^{*}$ & $-0.29^{* *}$ & 0.10 & 0.16 & 0.14 \\
\hline Vocabulary & $-0.35^{* *}$ & $-0.33^{* *}$ & $-0.36^{* *}$ & 0.17 & $0.28^{* *}$ & $0.24^{*}$ \\
\hline Block design & $-0.36^{* * *}$ & $-0.21^{*}$ & $-0.31^{* *}$ & 0.07 & 0.16 & 0.12 \\
\hline Picture arrangement & $-0.45^{* * *}$ & $-0.28^{* *}$ & $-0.39^{* * *}$ & -0.13 & -0.01 & -0.08 \\
\hline FSIQ & $-0.50^{* * *}$ & $-0.35^{* *}$ & $-0.45^{* * *}$ & 0.07 & 0.20 & 0.14 \\
\hline \multicolumn{7}{|l|}{ Continuous performance tests } \\
\hline Omission errors & $0.27^{*}$ & 0.19 & $0.25^{*}$ & -0.08 & -0.08 & -0.09 \\
\hline Commission errors & $0.34^{* *}$ & $0.30^{* *}$ & $0.34^{* *}$ & 0.02 & 0.02 & 0.02 \\
\hline Response times & 0.06 & 0.07 & 0.07 & $-0.23^{*}$ & -0.18 & $-0.22^{*}$ \\
\hline Response times variability & $0.29^{* *}$ & $0.29^{* *}$ & $0.31^{* *}$ & -0.05 & 0.00 & -0.03 \\
\hline \multicolumn{7}{|l|}{ Children's Color Trails Tests } \\
\hline CCTT 1 & 0.11 & 0.03 & 0.08 & -0.13 & 0.01 & -0.07 \\
\hline ССTT 2 & $0.37^{* * *}$ & $0.29^{* *}$ & $0.35^{* *}$ & -0.13 & -0.14 & -0.14 \\
\hline Interference & $-0.36^{* *}$ & $-0.29 * *$ & $-0.35^{* *}$ & 0.01 & 0.14 & 0.08 \\
\hline \multicolumn{7}{|l|}{ Stroop Color-Word Tests } \\
\hline Word & $-0.43^{* * *}$ & $-0.33^{* *}$ & $-0.41^{* * *}$ & -0.01 & 0.00 & -0.01 \\
\hline Color & $-0.39^{* * *}$ & $-0.30^{* *}$ & $-0.37^{* * *}$ & 0.03 & 0.08 & 0.06 \\
\hline Color-word & $-0.37^{* * *}$ & $-0.28^{* *}$ & $-0.34^{* *}$ & -0.03 & -0.02 & -0.03 \\
\hline Interference & 0.21 & 0.18 & 0.21 & -0.03 & -0.09 & -0.07 \\
\hline
\end{tabular}

${ }^{*} \mathrm{p}<0.05,{ }^{* *} \mathrm{p}<0.01,{ }^{* *} \mathrm{p}<0.001$. ADHD: attention-deficit/hyperactivity disorder, ARS: attention-deficit/hyperactivity disorder rating scale, KEDI-WISC: Korean Educational Development Institute-Wechsler Intelligence Scales for Children, FSIQ: full scale intelligent quotient 


\section{DISCUSSION}

This investigation examined the relationship between teacher-rated and parent-rated symptoms of ADHD and the neurocognitive function of children. Teacher ratings of inattention and hyperactivity/impulsivity were closely associated with children's cognitive performance in both a general population sample of children and in children with full-syndrome and subthreshold ADHD, but there were few significant relationships between parent-rated symptoms and cognitive performance especially in children with full-syndrome and subthreshold ADHD.

The level of agreement between teacher and parent ratings was low in children with full-syndrome and subthreshold ADHD and low to moderate in the normative sample. These results are consistent with some previous studies that found low to non-significant correlations between parent and teacher ratings for an ADHD sample ${ }^{3,28}$ and moderate correlations for typically developing children. ${ }^{6,7}$ The degrees of association were similar to those found in the present study. Parents and teachers appear to be reporting on important but distinct aspects of child functioning, and the lack of agreement on symptoms ratings may be due to variation in children's behavior in different situations and differences in the way different observers judge children's behavior. ${ }^{29}$

In the present study, we found that the association between ADHD symptoms and IQ and cognitive performance was stronger in teacher ratings than in parent ratings. These results are consistent with a previous finding, which showed a positive association of poor cognitive performance with teacher ratings of ADHD symptoms but not with parent ratings. ${ }^{30,31}$ Teachers may have a clearer opinion on ADHD symptoms than parents because they can make comparisons with other pupils, ${ }^{32}$ be familiar with age-appropriate behavior and better attuned to developmental changes in children. ${ }^{5}$ Parents generally reported higher behavioral problems than teachers, but teachers scored higher than parents on the items related to academic functioning. In contrast, parents are more sensitive than teachers to internalizing symptoms important for differential diagnosis of ADHD. ${ }^{33}$ Teacher observations of ADHD symptoms have been considered to be reliable and to agree with direct observation more than parent ratings, ${ }^{34}$ and to outperform parent ratings when considering sensitivity, specificity, and overall classification accuracy. ${ }^{33}$

Although there were only 20 children with full syndrome ADHD in our study, 68 with subthreshold ADHD were also included. Recently, there is increased interest in children who show inattentive or hyperactive/impulsive symptoms of ADHD but do not meet the diagnostic threshold, i.e. subthreshold ADHD. Subthreshold ADHD is reported to be more prevalent than full syndrome $\mathrm{ADHD},{ }^{35}$ associated with psychosocial adversity and functional impairment and related to a greater risk for developing clinical-level ADHD. ${ }^{36-38}$ Several researches which as- sessed the validity of subthreshold $\mathrm{ADHD}^{16,39-40}$ suggested that subthreshold ADHD might be a milder form of the disorder.

Children with full-syndrome and subthreshold ADHD showed significantly deficits in selective attention (increased omission errors on the CPT), sustained attention (increased response time variability on the CPT), response inhibition (increased commission errors on the CPT and lower color-word score on the Stroop Word-Color Test) in this study. These results are consistent with previous studies which addressed the core neurocognitive deficits of ADHD. ${ }^{2,41}$ However, there were no significant differences in Interference scores on the CCTT and Stroop tests between children with and without ADHD. Moreover, parent-rated and teacher-rated ADHD symptoms were not associated with the interference score on the Stroop test both in children with ADHD and in normative children. In recent meta-analysis, ${ }^{42}$ the Stroop interference effect was not larger in children with ADHD and significant differences in the Stroop test between children with $\mathrm{ADHD}$ and age-matched controls were found in the color and the color-word condition, congruent with our results. Further studies which addressed the Stroop interference effects in ADHD are needed. Some limitations should be considered in interpreting our findings. First, the moderate response rate and missing data of the teacher-rated and parent-rated ARS could lead to attrition bias. Second, because only third- and fourth-grade students were included, it is difficult to generalize our findings to the entire age range of children affected by ADHD. Future research with children in other age ranges may expand the current findings. Third, only 20 with full-syndrome ADHD among 580 children were included in the analysis, which is small number to generalize the results to entire population with ADHD. Despite these caveats, this study has the following strengths: a) a large community sample was assessed, minimizing selection bias; b) both general population of children and children with full-syndrome and subthreshold ADHD were evaluated; c) subjects in this study were recruited from a non-Western culture in Asia.

In conclusion, these results suggest that teacher ratings are more strongly associated than parent ratings with intelligence and cognitive performance in Korean children. Our results emphasize the importance of considering the teacher's report of a child's school functioning during the assessment of ADHD.

\section{Acknowledgments}

This study was supported by the Jeon Sang-Bae Child and Adolescent Research Fund of Korean Neuropsychiatry Research Foundation in 2000.

\section{REFERENCES}

1. Polanczyk G, de Lima MS, Horta BL, Biederman J, Rohde LA. The worldwide prevalence of ADHD: a systematic review and metaregression analysis. Am J Psychiatry 2007;164:942-948.

2. Barkley RA. Attention-deficit hyperactivity disorder: a handbook for diagnosis and treatment (3 ed). New York: The Guilford Press, 2006. 
3. Mitsis EM, McKay KE, Schulz KP, Newcorn JH, Halperin JM. Parentteacher concordance for DSM-IV attention-deficit/hyperactivity disorder in a clinic-referred sample. J Am Acad Child Adolesc Psychiatry 2000; 39:308-313.

4. Murray DW, Kollins SH, Hardy KK, Abikoff HB, Swanson JM, Cunningham C, et al. Parent versus teacher ratings of attention-deficit/hyperactivity disorder symptoms in the Preschoolers with Attention-Deficit/Hyperactivity Disorder Treatment Study (PATS). J Child Adolesc Psychopharmacol 2007;17:605-620.

5. de Nijs PF, Ferdinand RF, de Bruin EI, Dekker MC, van Duijn CM, Verhulst DC. Attention-deficit/hyperactivity disorder (ADHD): parents' judgment about school, teachers' judgment about home. Eur Child Adolesc Psychiatry 2004;13:315-320.

6. So YK, Noh JS, Kim YS, Ko SG, Koh SJ. The reliability and validity of Korean parent and teacher ADHD Rating Scale. J Korean Neuropsychiatr Assoc 2002;41:283-289.

7. Mares D, McLuckie A, Schwartz M, Saini M. Executive function impairments in children with attention-deficit hyperactivity disorder: do they differ between school and home environments? Can J Psychiatry 2007; 52:527-534.

8. Offord DR, Boyle MH, Racine Y, Szatmari P, Fleming JE, Sanford M, et al. Integrating assessment data from multiple informants. J Am Acad Child Adolesc Psychiatry 1996;35:1078-1085.

9. Gioia GA, Isquith PK, Kenworthy L, Barton RM. Profiles of everyday executive function in acquired and developmental disorders. Child Neuropsychol 2002;8:121-137.

10. Faraone SV, Biederman J, Zimmerman B. Correspondence of parent and teacher reports in medication trials. Eur Child Adolesc Psychiatry 2005; 14:20-27.

11. Bohnstedt BN, Kronenberger WG, Dunn DW, Giauque AL, Wood EA, Rembusch ME, et al. Investigator ratings of ADHD symptoms during a randomized, placebo-controlled trial of atomoxetine: a comparison of parents and teachers as informants. J Atten Disord 2005;8:153-159.

12. Oosterlaan J, Scheres A, Sergeant JA. Which executive functioning deficits are associated with $\mathrm{AD} / \mathrm{HD}, \mathrm{ODD} / \mathrm{CD}$ and comorbid $\mathrm{AD} / \mathrm{HD}+\mathrm{ODD} /$ CD? J Abnorm Child Psychol 2005;33:69-85.

13. Cho SC, Kim BN, Hong YC, Shin MS, Yoo HJ, Kim JW, et al. Effect of environmental exposure to lead and tobacco smoke on inattentive and hyperactive symptoms and neurocognitive performance in children. J Child Psychol Psychiatry 2010;51:1050-1057.

14. Dupaul GJ, Power TJ, Anastopoulos AD, Reid R. The ADHD rating scaleIV: Checklists, norm, and clinical interpretation. New York: Guilford Press, 1998.

15. Kim HW, Cho SC, Kim BN, Kim JW, Shin MS, Kim Y. Perinatal and familial risk factors are associated with full syndrome and subthreshold attention-deficit hyperactivity disorder in a korean community sample. Psychiatry Investig 2009;6:278-285.

16. Faraone SV, Biederman J, Doyle A, Murray K, Petty C, Adamson JJ, et al. Neuropsychological Studies of Late Onset and Subthreshold Diagnoses of Adult Attention-Deficit/Hyperactivity Disorder. Biol Psychiatry 2006; 60:1081-1087.

17. Shaffer D, Fisher P, Lucas CP, Dulcan MK, Schwab-Stone ME. NIMH Diagnostic Interview Schedule for Children Version IV (NIMH DISCIV): description, differences from previous versions, and reliability of some common diagnoses. J Am Acad Child Adolesc Psychiatry 2000;39:28-38.

18. Cho SC, Kim BN, Kim JW, Kim HW, Choi HJ, Jung SW, et al. The Reliability and Validity of Diagnostic Interview Schedule for Children Version IV-Korean Version (DISC-IV). J Korean Acad Child Adolesc Psychiatry 2007;18:138-144.

19. Park KS, Yoon JY, Park HJ, Park HJ, Kwon KU. Development of KEDIWISC, individual intelligence test for Korean children. Seoul: Korean Educational Development Institute; 1996.

20. Kaufman AS. A four test short form of the WISC-R. Contemp Educ Psychol 1976;1:180-196.

21. Greenberg LM, Waldman ID. Developmental normative data on the test of variables of attention (T.O.V.A.). J Child Psychol Psychiatry 1993;34: 1019-1030.

22. Shin MS, Cho SC, Chun SY, Hong KE. A study of the development and standardization of ADHD diagnostic system. J Child Adolesc Psychiatry 2000;11:91-99.

23. D’ Elia LF, Satz P, Uchiyama CL, White T. Color Trails Test: Professional manual. O Tdesa: Psychological Assessment Resources, 1996.

24. Koo HJ, Shin MS. A standardization study of children's color trails test. J Korean Acad Child Adolesc Psychiatry 2008:29-37.

25. Goldon CJ. A group version of the stroop color and word test. J Pers Assess 1975;39:386-388.

26. Shin MS, Park MJ. Stroop Color and Word Test: A Manual for Clinical and Experimental Uses. Seoul: Hakjisa; 2007.

27. Cicchetti DV. Guidelines, criteria, and rules of thumb for evaluating normed and standardized assessment instruments in psychology. Psychol Assess 1994;6:284-290.

28. Antrop I, Roeyers H, Oosterlaan J, Oost PV. Agreement between parent and teacher ratings of disruptive behavior disorders in children with clinically diagnosed ADHD. J Psychopathol Behav Assess 2002;24:67-73.

29. Van der Ende J. Multiple informants: Multiple views. In: Koot HM, Crijnen AAM, Ferdinand RF, editior. Child psychiatry epidemiology Accomplishments and future directions Assen: Van Gorcum \& Company, 1990, p.39-52.

30. Naglieri JA, Goldstein S, Delauder BY, Schwebach A. Relationships between the WISC-III and the Cognitive Assessment System with Conners' rating scales and continuous performance tests. Arch Clin Neuropsychol 2005;20:385-401.

31. Kuntsi J, Andreou P, Ma J, Borger NA, van der Meere JJ. Testing assumptions for endophenotype studies in ADHD: reliability and validity of tasks in a general population sample. BMC Psychiatry 2005;5:40.

32. Zeiner P. Parent-reported symptoms of hyperactivity and attention deficits predict teacher-reported symptoms. Acta Paediatr 1997;86:178-182.

33. Tripp G, Schaughency EA, Clarke B. Parent and teacher rating scales in the evaluation of attention-deficit hyperactivity disorder: contribution to diagnosis and differential diagnosis in clinically referred children. J Dev Behav Pediatr 2006;27:209-218.

34. Dupaul GJ, Power TJ, McGoey KE, Ikeda MJ, Anastopoulos AD. Reliability and validity of parent and teacher ratings of Attention-Deficit/Hyperactivity Disorder symptoms. J Psychoeduc Assess 1998;16:55-68.

35. Lewinsohn PM, Shankman SA, Gau JM, Klein DN. The prevalence and co-morbidity of subthreshold psychiatric conditions. Psychol Med 2004;34: 613-622.

36. Scahill L, Schwab-Stone M, Merikangas KR, Leckman JF, Zhang H, Kasl S, Psychosocial and clinical correlates of ADHD in a community sample of school-age children. J Am Acad Child Adolesc Psychiatry 1999;38:976-984.

37. Bird HR, Yager TJ, Staghezza B, Gould MS, Canino G, Rubio-Stipec M. Impairment in the epidemiological measurement of childhood psychopathology in the community. J Am Acad Child Adolesc Psychiatry 1990;29: 796-803.

38. Sanford MN, Offord DR, Boyle MH, Peace A, Racine YA. Ontario child health study: social and school impairments in children aged 6 to 16 years. J Am Acad Child Adolesc Psychiatry 1992;31:60-67.

39. Faraone SV, Kunwar A, Adamson J, Biederman J. Personality traits among ADHD adults: implications of late-onset and subthreshold diagnoses. Psychol Med 2009;39:685-693.

40. Cho SC, Kim BN, Kim JW, Rohde LA, Hwang JW, Chungh DS, et al. Full syndrome and subthreshold attention-deficit/hyperactivity disorder in a Korean community sample: comorbidity and temperament findings. Eur Child Adolesc Psychiatry 2009;18:447-457.

41. Willcutt EG, Doyle AE, Nigg JT, Faraone SV, Pennington BF. Validity of the executive function theory of attention-deficit/hyperactivity disorder: a meta-analytic review. Biol Psychiatry 2005;57:1336-1346.

42. Schwartz K, Verhaeghen P. ADHD and Stroop interference from age 9 to age 41 years: a meta-analysis of developmental effects. Psychol Med 2008; 38:1607-1616. 